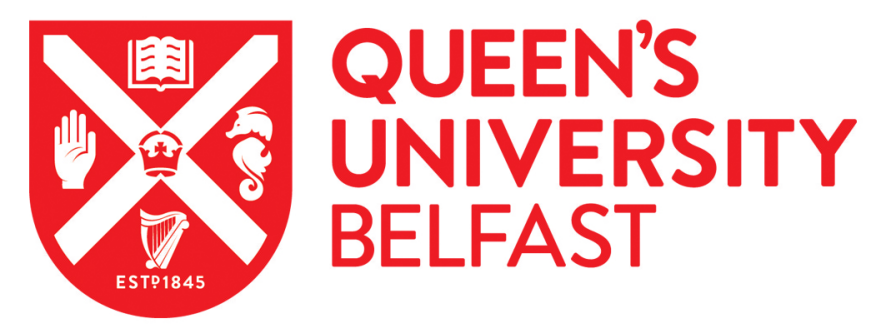

\title{
Assessment of transient stability support for electric vehicle integration
}

Zhou, B., Littler, T., \& Meegahapola, L. (2016). Assessment of transient stability support for electric vehicle integration. In Proceedings of the IEEE Power \& Energy Society General Meeting (PESGM 2016) Institute of Electrical and Electronics Engineers Inc.. https://doi.org/10.1109/PESGM.2016.7741347

Published in:

Proceedings of the IEEE Power \& Energy Society General Meeting (PESGM 2016)

Document Version:

Peer reviewed version

Queen's University Belfast - Research Portal:

Link to publication record in Queen's University Belfast Research Portal

Publisher rights

Copyright 2017 IEEE. This work is made available online in accordance with the publisher's policies. Please refer to any applicable terms of use of the publisher.

\section{General rights}

Copyright for the publications made accessible via the Queen's University Belfast Research Portal is retained by the author(s) and / or other copyright owners and it is a condition of accessing these publications that users recognise and abide by the legal requirements associated with these rights.

Take down policy

The Research Portal is Queen's institutional repository that provides access to Queen's research output. Every effort has been made to ensure that content in the Research Portal does not infringe any person's rights, or applicable UK laws. If you discover content in the Research Portal that you believe breaches copyright or violates any law, please contact openaccess@qub.ac.uk. 


\section{Assessment of Transient Stability Support for Electric Vehicle Integration}

\author{
Bowen Zhou, Student Member, IEEE \\ Tim Littler, Member, IEEE \\ School of Electronics, Electrical Engineering and Computer \\ Science \\ Queen's University Belfast \\ Belfast, UK \\ bruce233x@gmail.com; t.littler@qub.ac.uk
}

Lasantha Meegahapola, Member, IEEE

School of Electrical and Computer Engineering RMIT University

Melbourne, Australia

lasantha.meegahapola@rmit.edu.au

\begin{abstract}
Gradual escalation of electric vehicle (EV) penetration in modern power systems requires increasing support for EV charging. This additional demand represents a significant proportion of daily electric load which requires greater or flexible generation and transmission and poses challenges to system security and stability. This paper considers the impact of EV integration on transient stability by using an equivalent model of the Northern Ireland (NI) power system. The paper proposes an AC/DC converter-based EV aggregator model with two typical EV connections. A range of typical faults is investigated and discussed through simulation. The critical clearing time (CCT) and transient stability margin are used to assess transient stability on the NI system. Simulation results indicate that in order to achieve and sustain $2020 \mathrm{EV}$ integration targets and guarantee adequate transient stability, asset support and network reinforcement will be required and these outcomes are described in the paper.
\end{abstract}

Index Terms-electric vehicle (EV), power system, transient stability, critical clearing time (CCT), transient stability margin

\section{INTRODUCTION}

The UK government has made numerous efforts to reduce greenhouse gas (GHG) emission including transportation electrification. The UK government's strategy for ultra-low emission vehicles (ULEVs) establishes an unprecedented long-term commitment to advance transition to low-emission vehicles. The UK Office for Low Emission Vehicles (OLEV) continues to coordinate government support and organizes practical steps needed to position the UK at the forefront of this area [1]. It is anticipated that the UK will have 1.2 million battery electric vehicles (BEV) and 0.35 million plug-in hybrid electric vehicles (PHEV) by 2020; and, 3.3 million BEVs and 7.9 million PHEVs by 2030, [2]. In June 2015, there were approximately 37.3 million domestic road vehicles in the UK, of which, 35, 200 vehicles were EVs [3]. In Northern Ireland (NI) in particular, since April 2011, a comprehensive network of 334 public charge points has been installed for electric vehicles (EVs). The NI EV network is owned and operated by the Electricity Supply Board (ESB)
Group through its ESB car business. NI is a comparatively small region (population of 1.7 million) with the number of EVs in NI increasing from 5 in 2011 to 750 in July 2015 [4]. In comparison with the UK population (NI 2.9\% of the UK) [5] and vehicle proportions (NI 3\% of the UK) [6], it is estimated that there will be around $36,000 \mathrm{BEVs}$ and 10,500 PHEVs in NI by 2020 .

According National Grid, in a published Future Energy Scenarios document, [7] the total EV energy demand by 2020 will be $0.32 \%$ of the total UK annual electric demand. However, EV charging demand during mid-winter will peak at almost $26.6 \%$, which represents a significant load. Moreover, in a typical UK mid-winter, the average electricity customer currently consumes $13 \mathrm{kWh}$, but the expected average EV charge consumption will be approximately $6.3 \mathrm{kWh}$ per day, which means an increase of almost $50 \%$ in domestic consumption [8]. Although the overall forecast level of EV uptake by 2020 is not expected to represent an issue for the National Grid, EVs in particular locations will require local grid-reinforcement [9]. Therefore in terms of power systems, it is of significant importance to analyze the impact of largescale EV integration on stability.

In the broad context of power systems, transient stability refers to the ability of AC generators to remain in synchronous operation following a large disturbance. Maintaining transient stability is one of the most important priorities in power systems and is usually studied on a first-swing rather than a multi-swing basis. The critical clearing time (CCT) is usually adopted to evaluate transient stability [10]. Three methods are typically used to determine the CCT, which are extended equal-area criteria (EEAC), transient energy function (TEF), and time-domain simulation [10]. Since EEAC has limited accuracy [11] and it is difficult to construct an appropriate energy function [12], the time-domain simulation method has been widely used in practice to obtain the CCT.

In published work to date, there are two major approaches in the study of power system transient stability with largescale EV integration. The first approach considers EV
Engineering and Physical Sciences Research Council (EPSRC) UKChina joint research consortium (EP/F061242/1), the Science Bridge Award (EP/G042594/1), Chinese Scholarship Council (CSC) and Queen's

University Belfast, UK 
charging demand as an additional block in the system configuration while the power electronic converter is not included [13-14]. In this approach, transient stability retains its original definition and EV charging demand is integrated as part of the load. The second approach considers inclusion of power electronic converters whereby an EV aggregator model [15-20] is integrated and used during fault conditions [21-22]. In this latter approach, transient stability is defined as the capability of the EV aggregator - which is considered as a virtual power plant (VPP) - to remain in synchronous operation with the bulk power system and maintain the voltage level (and stability) within acceptable limits following large disturbances and typical faults. A large disturbance usually include short-circuit faults [21], loss of load and loss of generation [10]. However, typical faults for EV provision are not extensively classified. Since EV charging demand is usually obtained from discrete, time-domain values, a change in EV power demand, which can be regarded as a small stepdisturbance, should be well performed and excluded from the typical faults [22].

At present, there is limited published work on the impact of large-scale EV integration on transient stability. It is believed this is due to: 1) a perceived misunderstanding of the behavior of EVs - the common assumption being that they behave similar to energy storage systems (ESS); and 2) a lack of real and large-scale EV aggregators. Although optimal EV charging and discharging profiles are usually obtained hourly or half-hourly while transient stability simulations are up to 10 seconds in duration, in each time interval EV charging and discharging profiles remain constant, which reinforces a comparative similarity to an ESS. However, since EV charging demand is controllable and variable in each time interval, EVs can operate unlike ESSs [23]. Moreover, the lack of real, large-scale EV aggregators also limits any study in terms of practical verification, which limits model simulations to theoretical study.

This paper considers transient stability constraints and has used an equivalent model of the NI power system to assess capability and support for EV integration in 2020. Section II introduces an AC/DC converter-based EV aggregator model, followed in Section III by a brief discussion of two EV connections and typical faults. Section IV provides a definition of transient stability margin with EV integration and Section V presents a case study. Section VI concludes the findings of this paper.

\section{AC/DC CONVERTER-BASED EV AGGREGATOR MODEL}

A practical approach which considers external characteristic modelling is applied to construct an AC/DC converter-based EV aggregator model [17-20]. In comparison to previous work [17-18], the proposed model has fewer state variables and considers both the $\mathrm{AC}$ side (system) voltage and DC side (EV) voltage and a P-Q control algorithm. The equivalent model is shown in Figure 1.

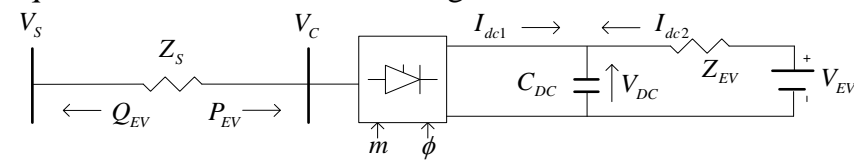

Figure 1. Equivalent AC/DC converter-based EV model
In Figure 1, Node $\mathrm{S}$ and Node $\mathrm{C}$ are the EV connection nodes with the power system and $\mathrm{AC}$ side bus of $\mathrm{EV}$ aggregator, respectively. $V_{S} \angle \delta_{S}$ and $V_{C} \angle \delta_{C}$ are the voltages of each node. $V_{E V}$ is the charging and discharging voltage and $V_{D C}$ is the voltage of the DC side bus. $P_{E V}$ is the EV charging power receiving from the systems and $Q_{E V}$ is the reactive power sending to the systems by the EV aggregator. The EV is connected to a power systems through a step-down transformer and $Z_{S}=j X_{S} \cdot Z_{E V}$ refers to the equivalent resistance of power loss inside the EV aggregator, and thus $Z_{E V}=R_{E V} . m$ and $\phi$ are the modulation ratio and phase of the equivalent converter and $\phi=\delta_{S}-\delta_{C}$ assuming $\mathbf{V}_{S}$ is leading $\mathbf{V}_{C}$. The bold letters refer to a phasor. In this paper, a voltage control converter with the pulse width modulation (PWM) strategy has been adopted. Therefore, the dynamic equations of the proposed model are shown as follows:

$$
\left\{\begin{array}{c}
\dot{V}_{D C}=\left(I_{d c 1}+I_{d c 2}\right) / C_{D C} \\
m=m_{r}+\left(K_{p a c}+K_{a c} / s\right)\left(V_{S r}-V_{S}\right) \\
\phi=\phi_{r}+\left(K_{p d c}+K_{d c} / s\right)\left(V_{D C r}-V_{D C}\right)
\end{array}\right.
$$

where $K_{p a c}, K_{a c}, K_{p d c}$, and $K_{d c}$ are the gains of the AC and DC voltage PI controller, respectively. Subscript $r$ refers the reference value. The voltage at AC side bus is,

$$
\mathbf{V}_{C}=m k V_{D C} \angle \delta_{C}=m k V_{D C} \angle \delta_{S}-\phi
$$

where $k$ is a constant dependent on the converter structure.

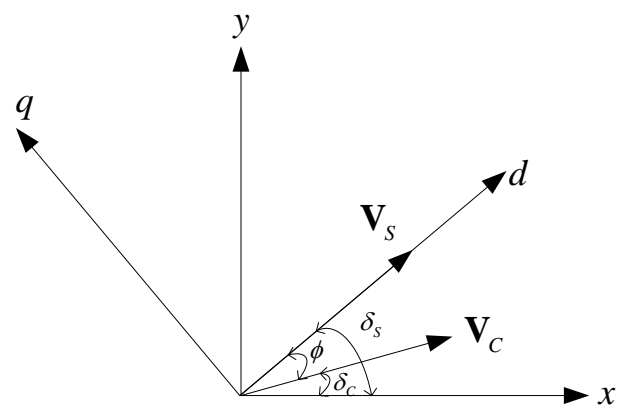

Figure 2. Phasor diagram in the d-q coordinate of the converter based unit

From Figure 1 and $2, \mathbf{V}_{C}=\mathbf{V}_{S}-j X_{S} \mathbf{I}_{S}$. Hence,

$$
\left\{\begin{array}{c}
I_{S d}=m k V_{D C} \sin \phi / X_{S} \\
I_{S q}=\left(m k V_{D C} \cos \phi-V_{S}\right) / X_{S}
\end{array}\right.
$$

Since, $V_{D C} I_{d c 1}=I_{S d} V_{C d}+I_{S q} V_{C q}=I_{S d} m k V_{D C} \cos \phi-I_{S q} m k V_{D C} \sin \phi$,

$$
I_{d c 1}=I_{S d} m k \cos \phi-I_{S q} m k \sin \phi
$$

Taking into account

$$
I_{d c 2}=\left(V_{E V}-V_{D C}\right) / R_{E V}
$$


Equations (1), (3), (4), and (5) render the full mathematical expression of the proposed model. Based on this model, the AC-side voltage, DC-side voltage and control of the model, as well as the active and reactive power can thus be expressed.

\section{EV CONNECTIONS AND TYPICAL FAULTS}

\section{A. EV connections}

Large-scale EV aggregators are usually connected in medium-voltage (MV) [19] or low-voltage (LV) [24] distribution networks. Two EV connection types are proposed according to the system structures, as shown in Figure 3.

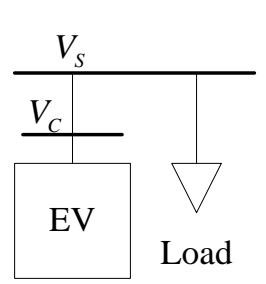

(a)

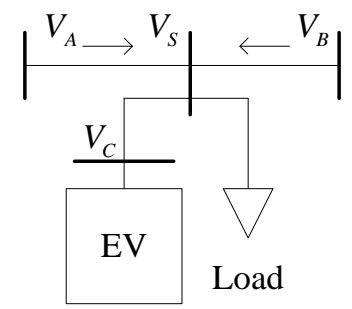

(b)
Figure 3. EV connections

In Figure 3, the block is a representative of EV model excluding $V_{S}, V_{C}$ and $Z_{S}$ in Figure 3 (a) shows EV connection at the receiving end of a radial network, while Figure 3 (b) shows EV connection at any node in a bulk power system. The load in Figure 3 can be zero if the EV aggregator is configured and connected with an independent node. Figure 3 (a) can be regarded as a single-load infinite-bus (SLIB) connection and Figure 3 (b) as a general connection.

\section{B. Typical faults}

With EV integration, typical faults include short-circuit faults and loss of load. The faults can be generally categorized as occurring on the system side, AC side of the EV aggregator and at the load side. It should be noted that in this study the detailed topology of EV aggregator is not specified, so faults inside the EV aggregator and the faults at the charger (EV side) are not considered. Typical faults are defined as:

\section{- SLIB type}

F1: Three-phase to ground fault at Node S (system side);

F2: Three-phase to ground fault at Node C (AC side);

\section{- General type}

F3: Three-phase to ground fault at Node B (system side);

F4: Three-phase to ground fault at Node C (AC side);

F5: Loss of load (load side).

A load-side fault in a SLIB is not included because Node $\mathrm{S}$ is an infinite bus and the load can be regarded as constant.

\section{TRANSIENT STABILITY MARGIN WITH EV INTEGRATION}

Assuming the bulk power system is a virtual generator, EEAC is applied to demonstrate the transient stability margin with EV integration. A typical power-angle curve of $P_{E V}$ over $\phi$ is given in Figure 4.

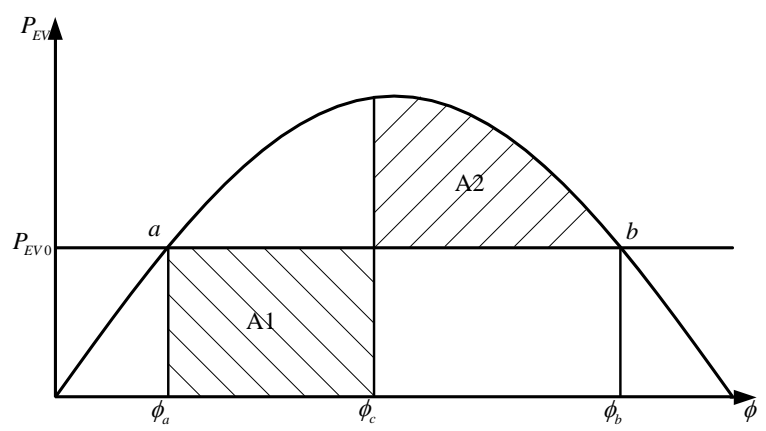

Figure 4. Power-angle curve of $P_{E V}$ over $\phi$

The transient stability margin is defined as the ratio of the deceleration area $\mathrm{A} 2$ over the acceleration area $\mathrm{A} 1$ under the same clearing time [11]. When the ratio is $=1$, the area of A1 equals the area of A2. This is a critical point for transient stability. When the ratio is $<1$, the system is transient unstable. When the ratio is $>1$, the system is transient stable. Hence, with a larger ratio, a larger margin is obtained. From Figure 4 it is apparent that when $P_{E V 0}$ is large, A1 is comparatively large and A2 smaller at the same clearing time, meaning that the transient stability margin is smaller. In practice, the transient stability margin is calculated in (6),

$$
\xi=\left(P_{E V \max }-P_{E V 0}\right) / P_{E V \max } \times 100 \%
$$

where $P_{E V \max }$ is the maximum $\mathrm{EV}$ charging demand at a certain CCT, which creates the critical point for transient stability. With any EV integration, $\xi$ is always $<1$. The value of $\xi$ is discussed as follows:

1) $0<\xi<1$ means the system is transient stable. The larger the value, the larger the margin;

2) $\xi=0$ means the system is critical, transient stable. The deceleration area equals to the acceleration area;

3) $\xi<0$ means the system is transient unstable. The actual EV charging demand $P_{E V 0}$ should be reduced.

\section{CASe STUdy}

\section{A. NI system description}

By 2020, it is expected there will be 67 nodes in the NI transmission system [25-28]. Based on the location of the 275 $\mathrm{kV}$ and $110 \mathrm{kV}$ transmission bus-bars among 26 local regions, an equivalent network model is obtained, as shown in Figure 5. In this network, 3 regions, named Ballymoney, Cookstown, and Moyle, are integrated into other regions, since there is no 275 or $110 \mathrm{kV}$ transmission grid in these regions. The other 23 regions are simplified as bus-bars and numbered from 1 to 23 in alphabetical order. 'To GB' and 'To IRE' refer to the interconnectors between NI and GB, and NI and Ireland. (?) 
and $\mathbb{W}$ refer to equivalent conventional generators and wind generators, respectively.

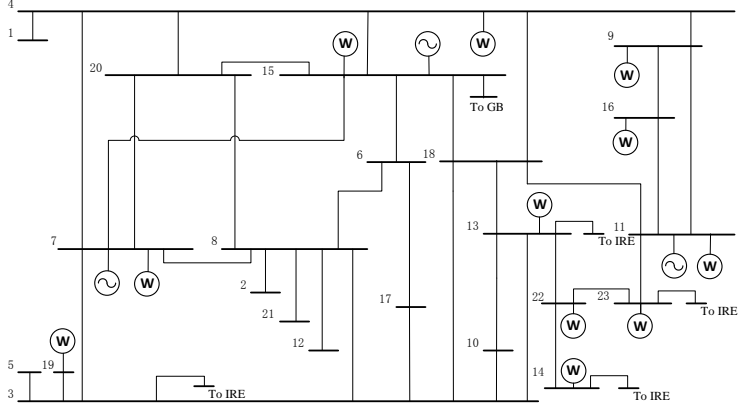

Figure 5. Simple equivalent NI system configuration

System characteristics and generation data in 2020 were obtained from [25-27] and load flow data from [28]. The load data, by region, were obtained from [29-30]. A PhillipsHeffron model [17] was adopted for the conventional generators and a $3^{\text {rd }}$ order, doubly-fed induction generator (DFIG) model [31] was considered for wind clusters/farms. Data of the EV model are shown in Table I.
TABLE I. DATA OF EV MODEL

\begin{tabular}{|c|c|c|c|c|c|c|c|}
\hline$V_{S r}$ & 1 & $V_{D C r}$ & 1 & $V_{E V}$ & 1 & $V_{C 0}$ & 1.01 \\
\hline$k$ & 5 & $C_{D C}$ & 1 & $X_{S}$ & 0.1 & $R_{E V}$ & 0.01 \\
\hline$K_{p a c}$ & 0.2 & $K_{a c}$ & 5 & $K_{p d c}$ & 0.2 & $K_{d c}$ & 5 \\
\hline
\end{tabular}

\section{B. Simulation approach and results}

In this case, a power flow solution for the NI 2020 wintermaximum scenario was obtained, which then calculates the CCT of different faults without EV connections. An EV aggregator is considered to be connected, one by one in different regions. As EVs are connected, power flow solutions and the maximum EV demand, with the same CCT (of the same fault) in the same region, are calculated. Taking into account standard EV charging power ratings [23], reference EV demand levels are obtained and compared with the calculated results. The typical UK commuter EV charging profile [7] is considered as the optimized EV daily demand. The results are shown in Table II.

TABLE II. TRANSIENT STABILITY MARGIN AND MAX EV SUPPORT NUMBER

\begin{tabular}{|c|c|c|c|c|c|c|c|c|c|}
\hline \multirow{2}{*}{ Region } & \multicolumn{3}{|c|}{ All EV charging } & \multicolumn{3}{|c|}{ UK commuter EV charging } & \multirow{2}{*}{$\begin{array}{c}\text { Max EV } \\
\text { demand (p.u.) }\end{array}$} & \multirow{2}{*}{$\begin{array}{l}\text { Max EV } \\
\text { number }\end{array}$} & \multirow{2}{*}{$\begin{array}{c}\text { Nominal EV } \\
\text { number }\end{array}$} \\
\hline & @7kW & @ 22kW & @50kW & @7kW & @ 22kW & @ 50kW & & & \\
\hline 1. Antrim & $1.8 \%$ & $-208.5 \%$ & $-601.2 \%$ & $90.2 \%$ & $69.1 \%$ & $29.9 \%$ & 0.1 & 1429 & 1402 \\
\hline 2. Ards & $84.5 \%$ & $51.3 \%$ & $-10.7 \%$ & $98.5 \%$ & $95.1 \%$ & $88.9 \%$ & 0.91 & 13000 & 2015 \\
\hline 3. Armagh & $-20.3 \%$ & $-278.1 \%$ & $-759.2 \%$ & $88.0 \%$ & $62.2 \%$ & $14.1 \%$ & 0.09 & 1286 & 1547 \\
\hline 4. Ballymena & $34.5 \%$ & $-106.0 \%$ & $-368.1 \%$ & $93.4 \%$ & $79.4 \%$ & $53.2 \%$ & 0.26 & 3714 & 2434 \\
\hline 5. Banbridge & $90.9 \%$ & $71.5 \%$ & $35.1 \%$ & $99.1 \%$ & $97.1 \%$ & $93.5 \%$ & 0.96 & 13714 & 1245 \\
\hline 6. Belfast & $-1506.8 \%$ & $-4949.9 \%$ & $-11377.0 \%$ & $-60.7 \%$ & $-405.0 \%$ & $-1047.7 \%$ & 0.035 & 429 & 6886 \\
\hline 7. Carrickfergus & $44.4 \%$ & $-74.6 \%$ & $-296.9 \%$ & $94.4 \%$ & $82.5 \%$ & $60.3 \%$ & 0.13 & 1857 & 1032 \\
\hline 8. Castlereagh & $-506.1 \%$ & $-1805.0 \%$ & $-4229.6 \%$ & $39.4 \%$ & $-90.5 \%$ & $-333.0 \%$ & 0.02 & 286 & 1732 \\
\hline 9. Coleraine & $27.0 \%$ & $-129.3 \%$ & $-421.1 \%$ & $92.7 \%$ & $77.1 \%$ & $47.9 \%$ & 0.14 & 2000 & 1459 \\
\hline 10. Craigavon & $44.9 \%$ & $-73.1 \%$ & $-293.5 \%$ & $94.5 \%$ & $82.7 \%$ & $60.7 \%$ & 0.31 & 4429 & 2440 \\
\hline 11. Derry & $-23.7 \%$ & $-288.9 \%$ & $-783.8 \%$ & $87.6 \%$ & $61.1 \%$ & $11.6 \%$ & 0.16 & 2286 & 2828 \\
\hline 12. Down & $84.6 \%$ & $51.5 \%$ & $-10.2 \%$ & $98.5 \%$ & $95.2 \%$ & $89.0 \%$ & 0.83 & 11857 & 1830 \\
\hline 13. Dungannon & $-955.6 \%$ & $-3217.5 \%$ & $-7439.8 \%$ & $-5.6 \%$ & $-231.8 \%$ & $-654.0 \%$ & 0.01 & 143 & 1508 \\
\hline 14. Fermanagh & $-470.1 \%$ & $-1691.8 \%$ & $-3972.3 \%$ & $43.0 \%$ & $-79.2 \%$ & $-307.2 \%$ & 0.02 & 286 & 1629 \\
\hline 15. Larne & $-118.9 \%$ & $-587.9 \%$ & $-1463.3 \%$ & $78.1 \%$ & $31.2 \%$ & $-56.3 \%$ & 0.04 & 571 & 1251 \\
\hline 16. Limavady & $-510.7 \%$ & $-1819.2 \%$ & $-4261.8 \%$ & $38.9 \%$ & $-91.9 \%$ & $-336.2 \%$ & 0.01 & 143 & 872 \\
\hline 17. Lisburn & $-205.5 \%$ & $-860.0 \%$ & $-2081.8 \%$ & $69.5 \%$ & $4.0 \%$ & $-118.2 \%$ & 0.07 & 1000 & 3055 \\
\hline 18. Magherafelt & $-1380.7 \%$ & $-4553.6 \%$ & $-10476.4 \%$ & $-48.1 \%$ & $-365.4 \%$ & $-957.6 \%$ & 0.01 & 143 & 2115 \\
\hline 19. Newry and Mourne & $54.6 \%$ & $-42.8 \%$ & $-224.6 \%$ & $95.5 \%$ & $85.7 \%$ & $67.5 \%$ & 0.4 & 5714 & 2596 \\
\hline 20. Newtownabbey & $-201.5 \%$ & $-847.7 \%$ & $-2053.9 \%$ & $69.8 \%$ & $5.2 \%$ & $-115.4 \%$ & 0.05 & 714 & 2154 \\
\hline 21. North Down & $-106.4 \%$ & $-548.6 \%$ & $-1374.1 \%$ & $79.4 \%$ & $35.1 \%$ & $-47.4 \%$ & 0.07 & 1000 & 2064 \\
\hline 22. Omagh & $63.1 \%$ & $-16.1 \%$ & $-163.8 \%$ & $96.3 \%$ & $88.4 \%$ & $73.6 \%$ & 0.26 & 3714 & 1372 \\
\hline 23. Strabane & $63.8 \%$ & $-13.8 \%$ & $-158.6 \%$ & $96.4 \%$ & $88.6 \%$ & $74.1 \%$ & 0.2 & 2857 & 1034 \\
\hline
\end{tabular}

From Table II, it can be seen that the transient stability margin decreases with an increase in charging rating. Only the Banbridge system is sufficient to support all EV charging at the same time at any power level. Two regions can support all EV charging at the $7 \mathrm{~kW}$ and $22 \mathrm{~kW}$ levels and eight regions are able to support all EV charging at $7 \mathrm{~kW}$. In other regions, at various power levels, transient stability is not assured. Thus, in this scenario, a system operator should be aware that large numbers of EVs cannot be simultaneously connected and the total EV charging demand should be limited to less than the maximum value.
When optimal EV charging profile is considered, the results improve. In this case, there are ten regions that would not be able to maintain transient stability with EV charging at some or all power levels. Therefore it is proposed that standard charging $(7 \mathrm{~kW})$ is recommended to all EV owners (in NI), based on statistical data and the outcomes and assumptions in this study. Only the total EV charging demand in Belfast, Dungannon, and Magherafelt should be assumed to be less than the maximum value. Moreover, it is recommended that grid-reinforcement with asset support and updates should be part of future planning to accommodate EV uptake in these regions. If standard charging is considered in 
all regions, twelve regions would not be capable of accommodating a nominal number of EVs. At best, NI is able to support, at most, $72,571 \mathrm{EVs}$ in 2020 , which is 1.56 times the 2020 projection.

\section{CONCLUSIONS}

This paper considers transient stability constraints in EV integrated power systems. An AC/DC converter-based EV aggregator model is proposed with two typical EV connections exemplified and typical faults discussed. A transient stability margin (with EV integration) is also introduced. The proposed model has been used for a transient stability analysis of the expected NI 2020 power system in order to EV support capability. Simulation results in this brief paper demonstrate a definite decrease in the transient stability margin with a consequent increase in EV charging ratings. Therefore, from this work, it is apparent that standard charging (of $7 \mathrm{~kW}$ ) is recommended to all EV owners (in NI) to maintain transient stability on the 2020 system. The paper has also concluded that the entire NI region is capable of supporting 1.56 times the projected 2020 EV provision; although grid and asset reinforcement will be required to reduce the impact on the stability margin (3 regions would be unable to maintain transient stability in the absence of system upgrading). This work provides timely and beneficial data for the transmission and distribution system operators (TSO, DSO) in terms of estimating the expected charging demand and anticipated grid and network-level investment required to accommodate large-scale EV integration (particularly for NI) in future power system planning.

\section{ACKNOWLEDGMENT}

The authors gratefully acknowledge Dr. Wenping Cao for his constructive comments and Ms. Macarena Martin Almenta for providing the data.

\section{REFERENCES}

[1] Department of Energy \& Climate Change, "Renewable Energy Roadmap UK Update 2013," [Online]. Available: https://www.gov.uk/government/uploads/system/uploads/attachment_d ata/file/255182/UK_Renewable_Energy_Roadmap_-_5_November_FINAL_DOCUMENT_FOR_PUBLICATIO_.pdf.

[2] B.W. Zhou, T. Littler, and H.F. Wang, "The impact of vehicle-to-grid on electric power systems: a review," in IET Renewable Power Generation Conference 2013, pp. 1-4, Sept. 2013.

[3] Department for Transport, "Vehicle licensing statistics: April to June 2015," [Online]. Available: https://www.gov.uk/government/statistics/vehicle-licensing-statisticsapril-to-june-2015

[4] E-car NI, "http://www.ecarni.com/ecarni-handover," [Online]. Available: http://www.ecarni.com/ecarni-handover

[5] Northern Ireland Statistics \& Research Agency, "Population and Migration Estimates Northern Ireland (2011) - Statistical Report," [Online].

Available: http://www.nisra.gov.uk/archive/demography/population/midyear/histo rical/mye_report_2011.pdf

[6] Department of Transport, "Vehicle licensing statistics: 2014," [Online]. Available: https://www.gov.uk/government/statistics/vehicle-licensingstatistics-2014

[7] National Grid, "UK Future Energy Scenarios," [Online]. Available: http://www2.nationalgrid.com/UK/Industry-information/Future-ofEnergy/Future-Energy-Scenarios/
[8] National Grid, "Journey of Discovery," 2014. [Online]. Available: http://www.nationalgridconnecting.com/journey-of-discovery/

[9] Office for Low Emission Vehicles, "Driving the future today: a strategy for ultra low emission vehicles in the UK," [Online]. Available: https://www.gov.uk/government/publications/driving-the-future-todaya-strategy-for-ultra-low-emission-vehicles-in-the-uk

[10] Prabha Kundur, Power System Stability and Control, New York: McGraw Hill, 1994.

[11] Zhengqiu Wu and Yong Jing, "Transient Stability Sensitivity Based on Time Domain Simulation," Proc. CSEE, vol. 21, no. 6, pp. 19-24, Jun. 2001.

[12] Theresa Odun-Ayo, and Mariesa L. Crow, "Structure-Preserved Power System Transient Stability Using Stochastic Energy Functions," IEEE Trans. Power Syst., vol. 27, no. 3, pp. 1450-1458, Aug. 2012.

[13] P.M. Rocha Almeida, F.J. Soares, J.A. Peças Lopes, "Electric vehicles contribution for frequency control with inertial emulation," Electric Power Systems Research, vol. 127, pp. 141-150, Oct. 2015.

[14] C. Gouveia, D. Rua, F.J. Soares, C. Moreira, P.G. Matos, J.A. Peças Lopes, "Development and implementation of Portuguese smart distribution system," Electric Power Systems Research, vol. 120, pp. 150-162, Mar. 2015.

[15] Saeed Rezaee and Ebrahim Farjah, "A DC-DC Multiport Module for Integrating Plug-In Electric Vehicles in a Parking Lot: Topology and Operation," IEEE Trans. Power Electron., vol. 29, no. 11, pp. 56885695, Nov. 2014.

[16] Michail Vasiladiotis and Alfred Rufer, "A Modular Multiport Power Electronic Transformer With Integrated Split Battery Energy Storage for Versatile Ultrafast EV Charging Stations," IEEE Trans. Industrial Electron., vol. 62, no. 5, pp. 3213-3222, May 2015.

[17] H. Cai, W. Du, Y.F. Rao, S. Gao, T. Littler and H.F. Wang, "PhillipsHeffron power system model for SmartPark and suppression of interarea oscillations", in IET Renewable Power Generation Conference 2013, pp. 1-4, Sept. 2013.

[18] P. Mitra, G. K. Venayagamoorthy, and K. A. Corzine, "SmartPark as a Virtual STATCOM", IEEE Trans. Smart Grid, vol. 2, no. 3, pp. 445455, Sept. 2011.

[19] Russell Crosier, and Shuo Wang, "DQ-Frame Modeling of an Active Power Filter Integrated With a Grid-Connected, Multifunctional Electric Vehicle Charging Station," IEEE Trans. Power Electron., vol. 28, no. 12, pp. 5702-5716, Dec. 2013.

[20] W. Du, H.F. Wang, J. Cao, H.F. Li, and L. Xiao, "Application of the Phase Compensation Method for the Design of a DC/AC ConverterBased Stabilizer to Damp Inter-Area Power Oscillations," IEEE Trans. Power syst., vol. 27, No. 3, pp.1302-1310, Aug. 2012.

[21] Diyun Wu, K. T. Chau, Chunhua Liu, Shuang Gao, and Fuhua Li, "Transient Stability Analysis of SMES for Smart Grid With Vehicle-toGrid Operation," IEEE Trans. on Appl. Superconductivity, vol. 22, no. 3, pp. 5701105, June 2012.

[22] P. Mitra and G.K. Venayagamoorthy, "Wide area control for improving stability of a power system with plug-in electric vehicles," IET Gener., Transm. Distrib., vol. 4, no. 10, pp. 1151-1163, 2010.

[23] Bowen Zhou, Tim Littler, and Aoife Foley, "Electric Vehicle Capacity Forecasting Model with Application to Load Levelling," in IEEE PES General Meeting 2015, pp. 1-5, Jul. 2015.

[24] Myriam Neaimeh, Robin Wardle, Andrew M. Jenkins, Jialiang Yi, Graeme Hill, Padraig F. Lyons, Yvonne Hübner, Phil T. Blythe, and Phil C. Taylor, "A probabilistic approach to combining smart meter and electric vehicle charging data to investigate distribution network impacts," Appl. Energy, in press.

[25] EirGrid, "Ten year transmission forecast statement 2014," [Online]. Available: http://www.eirgrid.com/media/2014AllIslandTenYearTransmissionForecastStatement.pdf

[26] EirGrid, "All-Island Transmission Forecast Statement 2012-2018," [Online]. Available: http://www.eirgrid.com/media/AllIsland $\% 20$ Transmission $\% 20$ Forecast $\% 20$ Statement $\% 202012 \% 20$ \%202018.pdf

[27] EirGrid, "All-Island Generator Capacity Statement 2015-2024," [Online].

Available: http://www.eirgrid.com/media/Eirgrid_Generation_Capacity_Statement _2015.-2024.pdf 
[28] EirGrid, "Ten year transmission forecast statement 2013," [Online]. Available: http://www.soni.ltd.uk/media/documents/Operations/AllIsland/Tenyeartransmssionforecaststatement2013.pdf

[29] Department of Energy \& Climate Change, "Sub-national domestic electricity consumption statistics in Northern Ireland," [Online]. Available: $\quad$ https://www.gov.uk/government/statistical-datasets/experimental-sub-national-domestic-electricity-consumptionstatistics-for-northern-ireland-2009
[30] Department of Energy \& Climate Change, "Sub-national non-domestic electricity consumption in Northern Ireland," [Online]. Available: https://www.gov.uk/government/statistical-data-sets/sub-national-nondomestic-electricity-consumption-in-northern-ireland-2010

[31] H. Cai, "Enhancement of Power System Dynamic Stability using Electric Vehicles and Distributed Generation," Ph.D. dissertation, Sch. of Electron., Electr. Eng. \& Comput. Sci., Queen's Univ. Belfast, Belfast, U.K., 2013. 